\title{
Met receptor signaling is required for sensory nerve development and HGF promotes axonal growth and survival of sensory neurons
}

\author{
Flavio Maina, ${ }^{1}$ Mark C. Hilton, ${ }^{2}$ Carola Ponzetto, ${ }^{3}$ Alun M. Davies, ${ }^{2}$ and Rüdiger Klein ${ }^{1,4}$ \\ ${ }^{1}$ Cell Regulation Programme, European Molecular Biology Laboratory, 69117 Heidelberg, Germany; ${ }^{2}$ School of Biological and \\ Medical Sciences, Bute Medical Buildings, University of St. Andrews, St. Andrews, Fife KY16 9TS, Scotland, UK; \\ ${ }^{3}$ Department of Biomedical Sciences and Oncology, University of Torino, 10126 Torino, Italy
}

\begin{abstract}
The development of the nervous system is a dynamic process during which factors act in an instructive fashion to direct the differentiation and survival of neurons, and to induce axonal outgrowth, guidance to, and terminal branching within the target tissue. Here we report that mice expressing signaling mutants of the hepatocyte growth factor (HGF) receptor, the Met tyrosine kinase, show a striking reduction of sensory nerves innervating the skin of the limbs and thorax, implicating the HGF/Met system in sensory neuron development. Using in vitro assays, we find that HGF cooperates with nerve growth factor (NGF) to enhance axonal outgrowth from cultured dorsal root ganglion (DRG) neurons. HGF also enhances the neurotrophic activities of NGF in vitro, and Met receptor signaling is required for the survival of a proportion of DRG neurons in vivo. This synergism is specific for NGF but not for the related neurotrophins BDNF and NT3. By using a mild signaling mutant of Met, we have demonstrated previously that Met requires signaling via the adapter molecule Grb2 to induce proliferation of myoblasts. In contrast, the actions of HGF on sensory neurons are mediated by Met effectors distinct from Grb2. Our findings demonstrate a requirement for Met signaling in neurons during devel opment.
\end{abstract}

[Key Words: Hepatocyte growth factor; nerve growth factor; Met; axonal growth; neuronal survival; signal transduction]

Received May 23, 1997; revised version accepted October 3, 1997.

The development of neurons in the peripheral nervous system (PNS) is a complex, yet highly stereotyped process that is controlled in part by external cues from other cells. Such cues include (1) factors that regulate the proliferation and differentiation of neuronal precursor cells, (2) factors that promote axonal outgrowth and guide axons to their targets, (3) survival factors that match the number of neurons to their targets, and (4) Iocal cues that refine initial connections by regulating terminal branching and synaptogenesis (Goodman and Shatz 1993; Davies 1994; Kennedy and Tessier-Lavigne 1995; Henderson 1996; Lewin and Barde 1996). Although much progress has been made in the identification of molecules with the above activities, in many cases it remains to be determined which of these molecules are actually required for PNS development. M oreover, many of these factors have multiple effects not only on neurons but also on

${ }^{4}$ Corresponding author.

E-MAIL klein@EMBL-Heidelbergde; FAX 496221387516. neighboring cells, making it difficult to distinguish between indirect target-mediated effects and direct effects on neurons.

One such pleiotropic factor is hepatocyte growth factor (HGF) which, besides promoting cell survival and proliferation of a number of cell types, stimulates cell migration and dissociation of epithelial sheets (Gherardi and Stoker 1991; Brinkmann et al. 1995). Through gene targeting experiments in mice, it was shown that HGF and its receptor, the $M$ et tyrosine kinase, are required for the development of placenta, liver, and muscle of the limbs and trunk (Bladt et al. 1995; Schmidt et al. 1995; Uehara et al. 1995; Maina et al. 1996). Met expression has al so been observed in various structures of the embryonic and postnatal nervous system, including spinal cord motor neurons and migrating neural crest cells (Sonnenberg et al. 1993; Jung et al. 1994; Andermarcher et al. 1996). Recently, HGF was shown to be a chemoattractant and survival factor for spinal motor neurons in vitro (Ebens et al. 1996). In addition, hgf $-1-$ mice showed 
marked defects in limb nerve branching. However, because motor neurons depend on extrinsic factors provided by muscle cells and because the HGF/M et system is required for muscle development, this study did not provide conclusive evidence for a requirement of $\mathrm{M}$ et signaling in motor neurons.

To study target-independent functions of HGF, we have focused on the development of sensory neurons that innervate the skin of the limbs and thorax, as in contrast to motor neurons, their projections are not influenced by cues on muscle cells (Lewis et al. 1981). Here we show that mice carrying a signaling mutant of $M$ et (met $^{\mathrm{D} / \mathrm{D}}$ ) have intercostal nerves that are much reduced in length and elaborate fewer terminal branches, demonstrating a requirement for $\mathrm{HGF} / \mathrm{M}$ et signaling in sensory neuron development. Using in vitro assays, we find that HGF cooperates with nerve growth factor (NGF) in enhancing the axonal growth rate of dorsal root ganglion (DRG) sensory neurons. In addition, HGF enhances the neurotrophic activities of N GF in vitro, and $M$ et receptor signaling is required for the survival of a proportion of DRG neurons in vivo.

Previous work on $\mathrm{M}$ et receptor signaling has revealed that the biological activity of Met depends on the presence of two phosphotyrosine residues in the carboxyterminal tail, which act as multifunctional docking sites for SH2-containing effectors and activate an array of transductional pathways (Ponzetto et al. 1994). M utation of both tyrosine residues in the mouse genome $\left(\right.$ met $^{\mathrm{D} / \mathrm{D}}$ ) is lethal and causes defects identical to the phenotype of met null mutants (M aina et al. 1996). In contrast, a mild mutation of $M$ et (met ${ }^{\mathrm{Grb} 2 / \mathrm{Grb} 2}$ ), in which the direct binding of Grb2 is uncoupled (Ponzetto et al. 1996), revealed an additional function of $M$ et during myogenesis (M aina et al . 1996). M et signal ing via Grb2 is requi red for myoblast proliferation but not for myoblast migration or for survival of hepatocytes. In this report we have shown that in contrast to its myogenic function, M et signaling via Grb2 is not required for sensory neuron devel opment.

\section{Results}

Limb motor innervation defects correlate with reduction of muscle in met mutant embryos

To investigate whether $M$ et signaling is required for the development of the PNS, we examined wild-type and mutant embryos in which met was replaced with lossof-function versions of the receptor impaired in signal transduction (met ${ }^{\mathrm{Grb} 2 / \mathrm{Grb} 2}$, met ${ }^{\mathrm{D} / \mathrm{D}}$ ). The most severe of these mutants (met ${ }^{D / D}$ ), like homozygous Spl otch mice (Franz et al . 1993) [in which pax-3, an upstream regulator of met (Epstein et al . 1996), is mutated], specifically lack muscles derived from migratory precursors, such as limb and shoulder muscles (M aina et al. 1996). Whole-mount immunostaining with anti-neurofilament antibodies showed that, at embryonic day 12.5 (E12.5) in met ${ }^{\mathrm{D} / \mathrm{D}}$ embryos, the brachial plexus in the forelimb is appropriately patterned, but all nerves emanating from it are shortened dramatically and lack branching (Fig. 1C,F).
Figure 1. Abnormal limb innervation in mice carrying mutant alleles of the $M$ et receptor gene. (A-C) Whole-mount, anti-neurofilament-stained E12.5 mouse embryos (forelimb and thorax region, dorsal up, anterior left) carrying either the wild-type knock-in allele of met (met $\left.^{W T / W T}\right)(A, D, G)$, a mild signaling mutant (met $\left.{ }^{\mathrm{Grb2} / \mathrm{Grb2}}\right)(\mathrm{B}, \mathrm{E}, \mathrm{H})$, or a severe signaling mutant (met $\left.{ }^{\mathrm{D} / \mathrm{D}}\right)(\mathrm{C}, \mathrm{F}, \mathrm{I})$. (D-F) Drawings of limb nerves. N ote the severely reduced length and lack of terminal branching of all limb nerves in the met ${ }^{\mathrm{D} / \mathrm{D}}$ mutant embryo (F). In met ${ }^{\mathrm{Grb2} / \mathrm{Grb2}}$ mutants, the nervus radialis is severely affected, which could explain the observed deficiency in forelimb extension in met $^{\mathrm{Grb2} / \mathrm{Grb} 2}$ newborn mice (Maina et al. 1996). (G-I Forelimbs of whole-mount, anti-neurofilament-stained E12.5 mouse embryos before clearing, showing the superficial innervation of the skin. The defects are fully penetrant with six out of six embryos affected. Some met ${ }^{\mathrm{D} / \mathrm{D}}$ mutant embryos also show misdirection of spinal nerves that innervate the hindlimb (data not shown). (N .ax.) nervus axillaris; ( $\mathrm{N}$. med.) nervus medianus; (N.mu) nervus musculocutaneus; (N.ra.) nervus radialis; (N.th.) nervus thoracodorsalis; (N.ul.) nervus ulnaris. Scale bar in A-C, $1.1 \mathrm{~mm}$; in (G-I) $0.6 \mathrm{~mm}$.

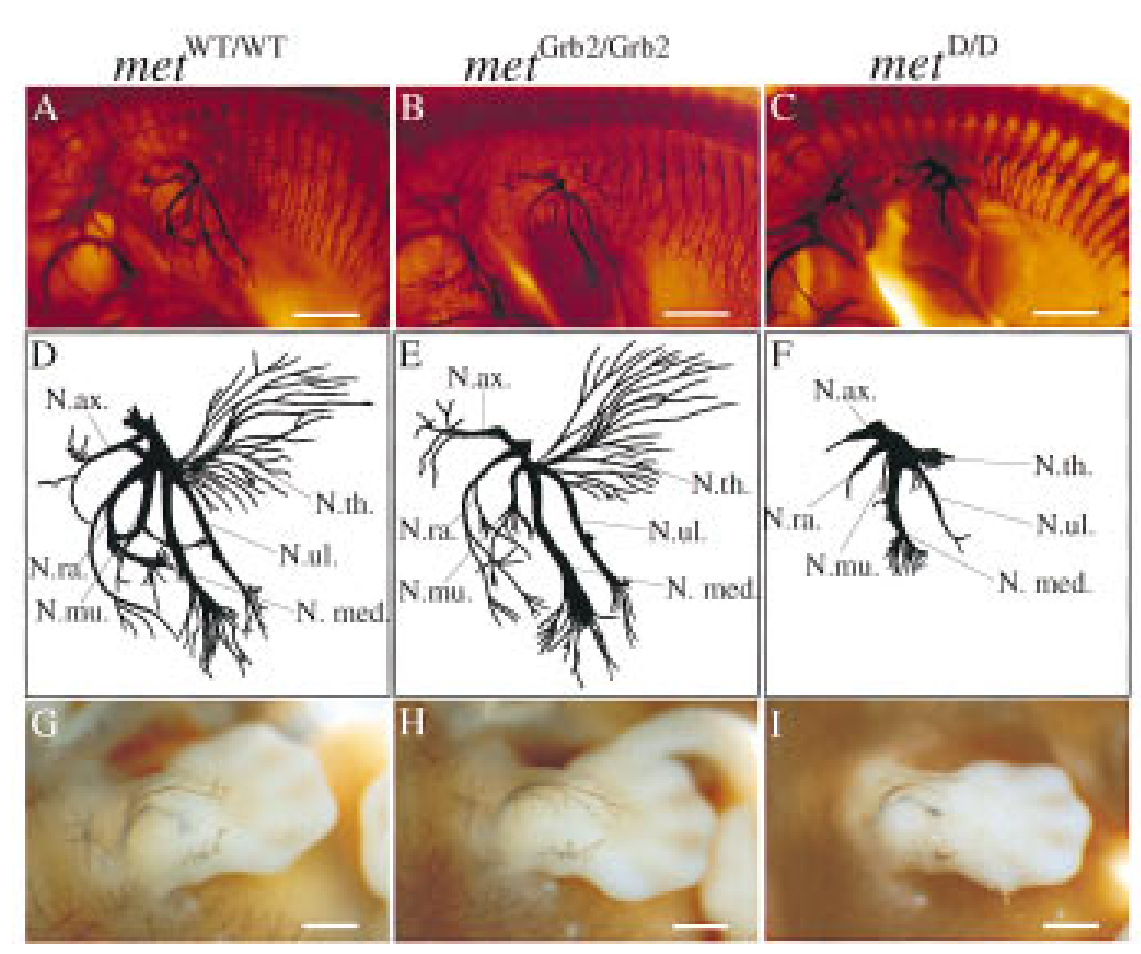


For example, all branches of the nervus thoracodorsalis, which contains only motor fibers that innervate the musculus latissimus dorsii (lost in these mutants), are completely absent in met ${ }^{\mathrm{D} / \mathrm{D}}$ embryos. Mutant embryos carrying the milder met ${ }^{\mathrm{Grb} 2 / \mathrm{Grb} 2}$ allele, where the same muscle is reduced but not absent, showed that branching of the nervus thoracodorsal is is indistinguishable from that of met ${ }^{W T / W T}$ control embryos (Fig. 1A,B,D,E). In met $^{\mathrm{Grb} 2 / \mathrm{Grb} 2}$ mutants, only the most anterior limb nerves (nervus radialis and musculocutaneous), innervating an area of the limb where the reduction of muscles is more pronounced (M aina et al. 1996), are affected (Fig. 1B,E). This innervation defect correl ates with the reduction in muscle mass and could be secondary to the lack of muscles.

Reduced outgrowth and branching of sensory nerves in the limbs and thorax of met mutant mice

In contrast to motor nerves, the development of sensory nerve fibers in the limb is not dependent on the presence of limb muscles (Lewis et al. 1981), The superficial network of sensory nerves in the skin is reduced drastically in met ${ }^{\mathrm{D} / \mathrm{D}}$ mutants, both in the limbs (Fig. 1I) and the trunk region. Interestingly, the branches of superficial skin nerves appear to be normal in met ${ }^{\mathrm{Grb} 2 / \mathrm{Grb} 2}$ mutants (Fig. $1 \mathrm{H}$ ). To better define the effects of $M$ et signaling independent of its myogenic role in neurons in the limb, we performed a detailed anal ysis of the peripheral nerves innervating the trunk region. As shown in Figure 2, the development of thoracic spinal nerves is severely affected in E12.5 met $^{\mathrm{D} / \mathrm{D}}$ mutant embryos compared to met $^{\mathrm{WT} / \mathrm{WT}}$ control embryos. Both the dorsal and ventral arms of the lateral cutaneous branches, which innervate the skin and muscle of the thorax, are severely compressed with much fewer ramifications than controls (Fig. 2A,C,D , F). The defect is most prominent in the superficial ventral arms, which sprout significantly fewer side branches, and are reduced in length by an average of $>60 \%$ compared to met ${ }^{\mathrm{WT} / \mathrm{WT}}$ embryos or heterozygous littermates (Fig. 2G-I; data not shown). Similar analysis on E13.5 mutant embryos reveal ed the same defects, suggesting that the lack of nerve branching was not caused by a general delay in embryonic development (data not shown). The overall patterning of the spinal nerve network, however, appears to be preserved in met $^{\mathrm{D} / \mathrm{D}} \mathrm{mu}-$
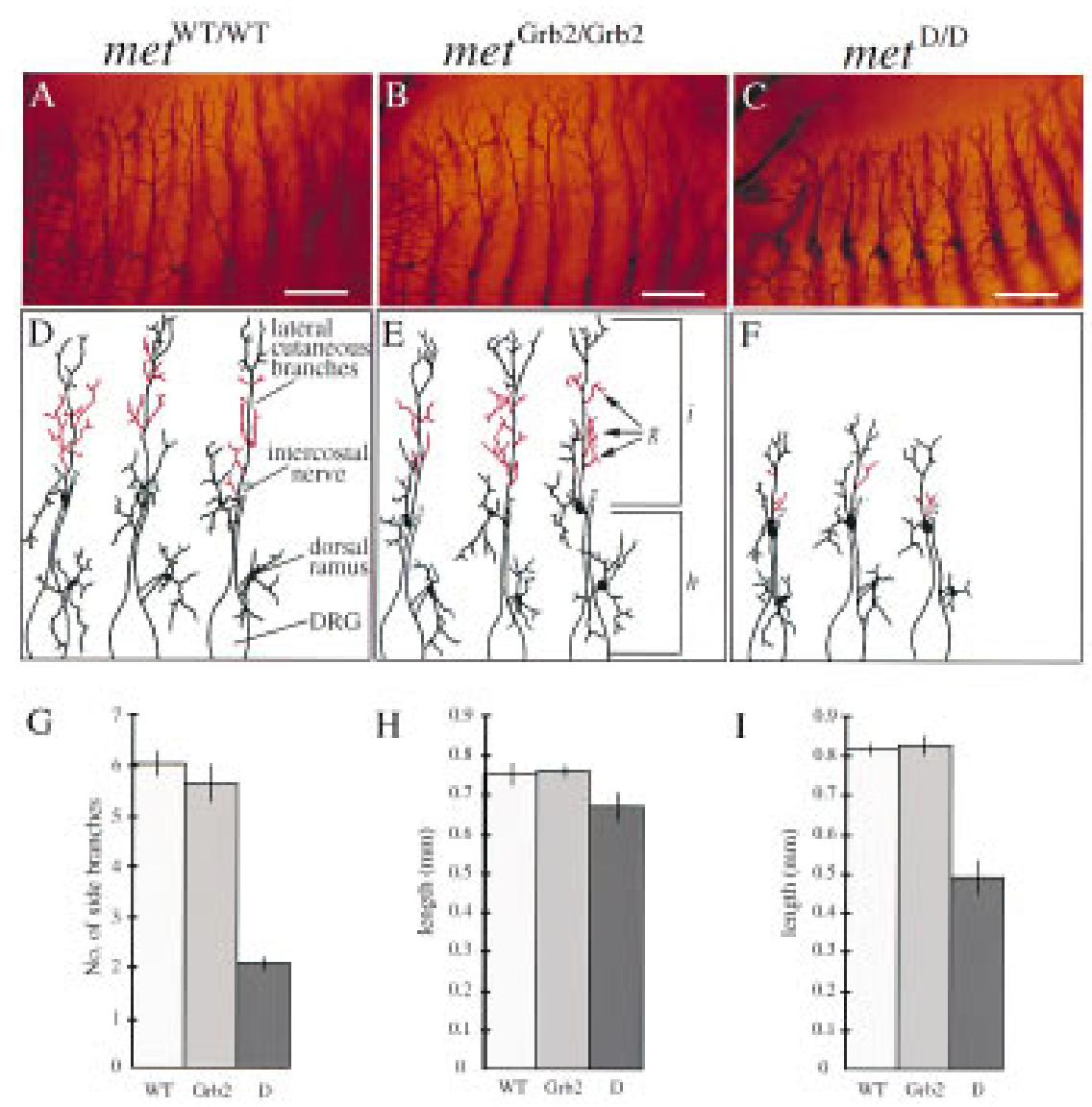

H

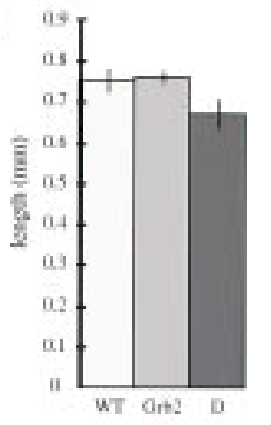

1

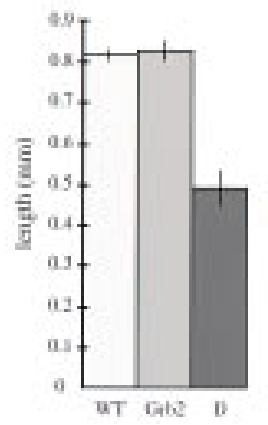

Figure 2. Defects in spinal nerve outgrowth and branching in met mutant mice. (A-C) Anti-neurofilament-stained ventral branches of thoracic spinal nerves (dorsal down, ventral up). $\mathrm{N}$ ote the reduction in length and numbers, and the compressed appearance of side branches in the met ${ }^{\mathrm{D} / \mathrm{D}}$ mutant embryos (C). (D-F) Representative drawings of thoracic DRG and spinal nerves. Only dorsal rami and lateral cutaneous branches are shown; the distal end of the intercostal nerve does not appear to be affected and is omitted for clarity. (G-I) Quantitative analysis of the defects in spinal nerve development. (E) The parameters that were used for quantification. (G) The number of side branches (indicated in red in $\mathrm{D}-\mathrm{F}$ ) were determined between the origin of the lateral cutaneous branch and the point where the main axon bundle divides into two or three equally sized terminal projections. $(\mathrm{H})$ Length of the most proximal part of the peripheral axon bundle measured from the exit points of the central processes of the DRG to the origin of the lateral cutaneous branch. (I) Length of the most distal arms of the lateral cutaneous branch. Note that the length of the proximal part of the spinal nerve does not change in met ${ }^{\mathrm{D} / \mathrm{D}}$ mutant embryos. In contrast, there is a strong reduction in length of the most distal arms of the lateral cutaneous branch in met ${ }^{\mathrm{D} / \mathrm{D}}$ mutant embryos compared to the controls (statistical analysis was carried out using Student's t-test; $\mathrm{P}<0.0001$ ). Similar results were obtained using an antibody against neuron-specific tubulin (data not shown). N o significant differences in the number of ramifications or length of spinal nerves were observed in met ${ }^{G r b 2 / G r b 2}$ embryos compared to met ${ }^{\mathrm{WT} / \mathrm{WT}}$. Four peripheral axon bundles, from three different mutant mice, for each genotype, were analyzed. Scale bar in A-C, $0.3 \mathrm{~mm}$. 
tant embryos, suggesting a role for $M$ et signaling in terminal nerve growth and branching, rather than in initial axonal guidance. In contrast, met ${ }^{\mathrm{Grb2} / \mathrm{Grb2}}$ mutant embryos are indistinguishable from their wild-type littermates (Fig. 2B,E,G-I), indicating that Grb2 signaling downstream of $M$ et is not required for peripheral nerve growth and branching.

HGF cooperates with NGF to enhance axonal outgrowth from cultured DRG neurons

To investigate whether HGF-induced Met signaling directly affects the growth of axons from wild-type DRG neurons, we studied the effect of HGF al one and in combination with other neuritogenic factors, such as NGF, brain-derived neurotrophic factor (BDNF), and neuro-
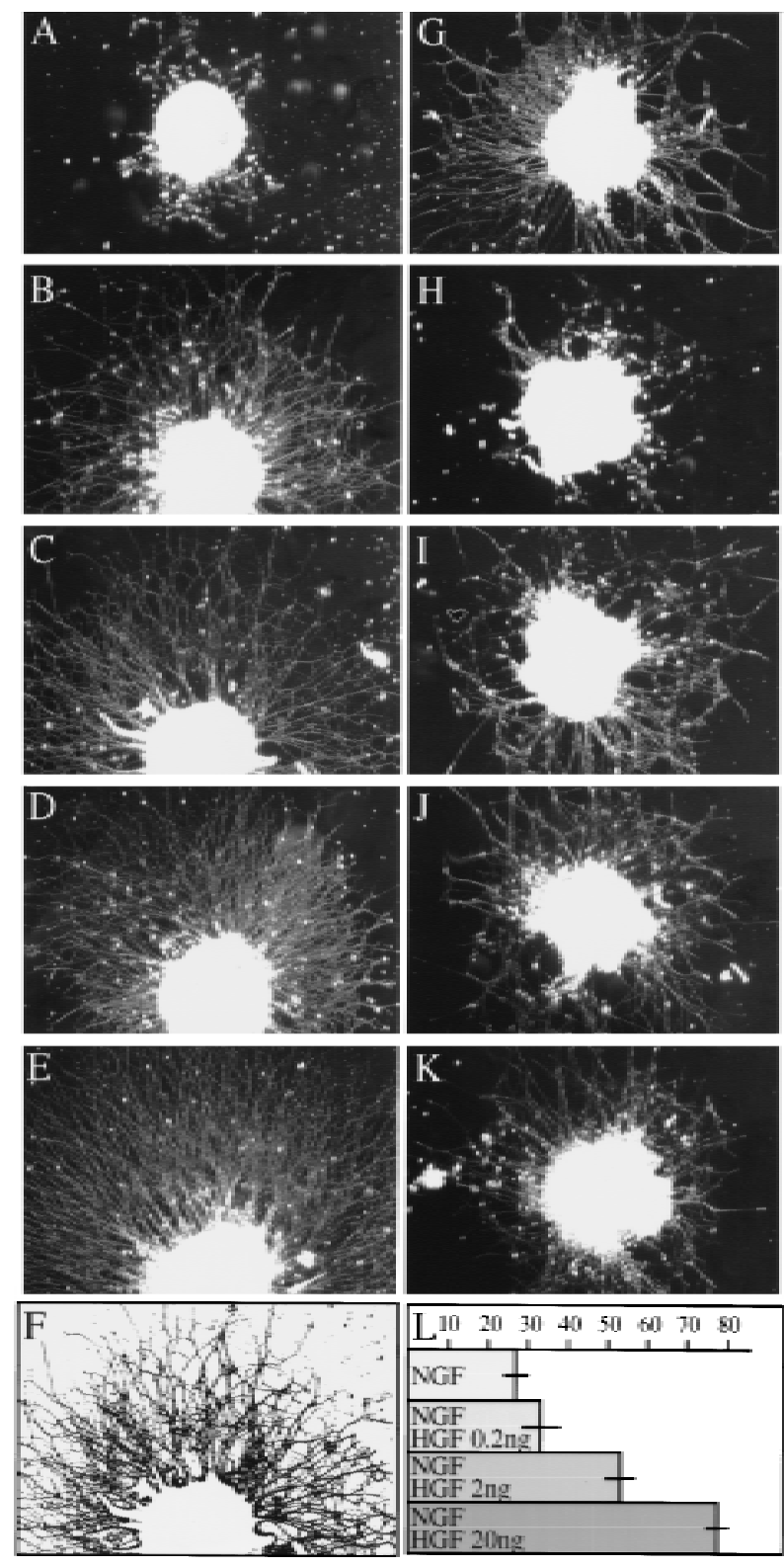

trophin-3 (NT3) (Davies 1994; Schnell et al. 1994; McAllister et al. 1995; Henderson 1996; Lewin and Barde 1996), on neurite outgrowth from DRG explants. AIthough HGF al one had no outgrowth-promoting activity on cultured DRG explants (Fig. 3A), it dramatically enhanced NGF-promoted neurite outgrowth. In the presence of HGF plus NGF, neurite bundles were longer and showed more numerous ramifications than explants treated with NGF al one (Fig. 3B-E). Quantification of digitalized images reveal ed a threefold increase in neurite density in NGFHHF-treated DRGs compared to N GF-treated explants (Fig. 3F, L). Saturation of these effects was observed between 10 and $20 \mathrm{ng} / \mathrm{ml}$ of HGF (data not shown).

Interestingly, HGF, in combination with BDNF and NT3, had no significant neurite outgrowth-enhancing effect (Fig. 3l-K), suggesting that the effects of HGF are confined to the NGF-dependent subpopulation of painand temperature-sensitive DRG neurons (Crowley et al. 1994; Smeyne et al. 1994; Wall 1995; Indo et al. 1996). The cooperative effect of NGF and HGF on neurite outgrowth was further verified by using neutralizing antibodies. Anti-HGF antibodies ( $1 \mu \mathrm{g} / \mathrm{ml}$ ) blocked the enhancing effect of HGF, whereas anti-N GF antibodies (1 $\mu \mathrm{g} / \mathrm{ml}$ ) inhibited neurite outgrowth completely (Fig. $3 \mathrm{G}, \mathrm{H})$. These findings indicate that HGF requires NGF for its outgrowth-promoting activity.

To further confirm the neuritogenic activity of HGF, we set up DRG explant cultures from met ${ }^{D / D}$ and met $^{\mathrm{Grb2} / \mathrm{Grb} 2}$ mutants. Control cultures from met ${ }^{\mathrm{WT} / \mathrm{WT}}$ embryos of the same $129 \times \mathrm{C} 57 \mathrm{BI} / 6$ mixed background showed strong enhancement of neurite outgrowth after treatment with HGF plus NGF, compared to NGF al one (Fig. 4A,D). Likewise, DRG explants derived from embryos carrying the mild met ${ }^{\mathrm{Grb2} / \mathrm{Grb} 2}$ allele showed robust HGF-enhanced outgrowth (Fig. 4B,E). In contrast, no significant HGF effect was observed in DRG explants

Figure 3. N eurite outgrowth of E12.5 DRG explants from wildtype embryos cultured in the presence of different growth factors. Photomicrographs show DRG explants cultured for $20 \mathrm{hr}$ in the presence of HGF (12 ng/ml) (A), NGF $(5 \mathrm{ng} / \mathrm{ml})(B), N G F$ $(5 \mathrm{ng} / \mathrm{ml}$ ), plus HGF at varying concentrations (C, $0.2 \mathrm{ng} / \mathrm{ml} ; \mathrm{D}$, $2 \mathrm{ng} / \mathrm{ml}$; E, $20 \mathrm{ng} / \mathrm{ml}$ ). (G,H) N GF +HGF (5 and $12 \mathrm{ng} / \mathrm{ml}$, respectively) with neutralizing antibodies against $\mathrm{HGF}(\mathrm{G})$ or NGF $(\mathrm{H})(1 \mu \mathrm{g} / \mathrm{ml})$. BDN F +NT3 $(5 \mathrm{ng} / \mathrm{ml}$ each) al one (I) or with HGF (J) $(12 \mathrm{ng} / \mathrm{ml})$. (K) BDNF + NT3 + HGF with neutralizing antibodies against HGF $(1 \mu \mathrm{g} / \mathrm{ml})$. N ote that neurite outgrowth was more extensive from explants stimulated by NGF + HGF than from explants grown with NGF alone. In contrast, HGF had no significant outgrowth-enhancing effect on DRGs in cultures treated with BDNF+NT3. Neutralizing antibodies against HGF blocked the enhancing effect of HGF, whereas antiNGF antibodies completely inhibited neurite outgrowth. (L) Quantification of digitalized images (one representative example is shown in F). N umbers represent pixels per inch ${ }^{2}$. These data reveal a progressive increase in total surface of neuronal processes of DRGs treated with NGF + HGF compared to NGF only. Three to seven experiments were done, in quadruplicate, for each condition. 
derived from the severe met ${ }^{\mathrm{D} / \mathrm{D}}$ mutants (Fig. 4C,F). DRGs from met ${ }^{\mathrm{D} / \mathrm{D}}$ embryos treated with BDNF plus NT3 are indistinguishable compared to the controls, confirming that the defects are confined to the NGFdependent subpopulation of neurons (data not shown).

\section{Met receptors are expressed on sensory neurons}

To establish that the effects of HGF were directly transduced by $M$ et receptors expressed on DRG neurons, we immunostained with antibodies against human $M$ et DRG explants derived from met $^{\mathrm{Grb2} / \mathrm{Grb2}}$ mutants, which carry the human CDNA in the met locus. Figure 5 shows positive staining for human $M$ et in axons and growth cones $(B)$ of DRG neurons that were stimulated by NGF plus HGF. Much weaker staining was observed on DRG explants derived from wild-type embryos because of weak cross-reactivity of the antibodies with mouse Met (data not shown). The positive signal obtained with the anti-human Met antibodies was competable with the corresponding peptide used as antigen (Fig. 5C). RT-PCR analysis in dissociated, highly purified DRG neuron cultures further confirmed met expression in DRG neurons (Fig. 5E).

HGF cooperates with NGF to enhance the axonal growth rate of dissociated sensory neurons

Because enhanced neurite outgrowth from ganglion explants could be attributable to an increase in axonal growth rate or improved neuronal survival, or both, we studied the effects of HGF and N GF on the growth rate of axons from DRG neurons grown in dissociated culture. The axonal growth rate of individual E12 (Fig. 6) and E13 (data not shown) DRG neurons was markedly enhanced in the presence of HGF plus NGF, compared to NGF alone, demonstrating that HGF does enhance the axonal growth rate of neurons surviving with NGF. Furthermore, because these results were obtained from neurons growing at very low density, these results further indicate that HGF exerts a direct effect on NGF-dependent neurons rather than acting indirectly on other cells.
HGF enhances the survival of cultured DRG neurons supported by NGF but not by BDNF or NT3

Programmed cell death of DRG neurons caused by competition for limited amounts of target-derived survival factors occurs between E11 and E17 in the mouse (Farinas et al . 1996; White et al . 1996). To determine whether HGF, in addition to its effects on axonal growth, al so has neurotrophic activity, DRG neurons were isolated from E12 mouse embryos, dissociated and cultured in defined medium without added factors, with HGF, neurotrophins, or with combinations of factors. DRG neurons cultured without added factors or with HGF at concentrations ranging from 1 to $25 \mathrm{ng} / \mathrm{ml}$ died rapidly (data not shown). However, there were substantially more neurons surviving in cultures containing HGF plus NGF compared with cultures containing N GF al one (Fig. 7A). Cohort experiments, in which the fates of individual cells were followed at intervals, indicated that this increase in the number of surviving neurons was the result of two effects of HGF. In the presence of NGF, HGF not only increased the survival time of differentiated neurons but also increased the number of neurons that differentiated from progenitor cells in culture (Fig. 7A). In contrast to the enhanced survival of NGF-dependent neurons, HGF did not increase the number of sensory neurons treated with either NT3 (Fig.7B) or BDN F (Fig. 7C), despite the fact that $M$ et is expressed in BDNF- and NT3-dependent neurons in culture (Fig. 5E). HGF also failed to enhance the effects of higher concentrations of BDNF (50 ng/ml; data not shown), which further supported the specific interaction between HGF and NGF.

Met signaling is required for the survival of a subset of DRG neurons in vivo

N ext we analyzed whether the neurotrophic activity of HGF would be required for survival of DRG neurons in vivo. Although the absolute number of apoptotic nuclei varied from experiment to experiment, there was a consistent increase in cell death in the mutant embryos. TUNEL staining of DRG sections either preceding (E11.5) or during the period of Met-dependent neurite
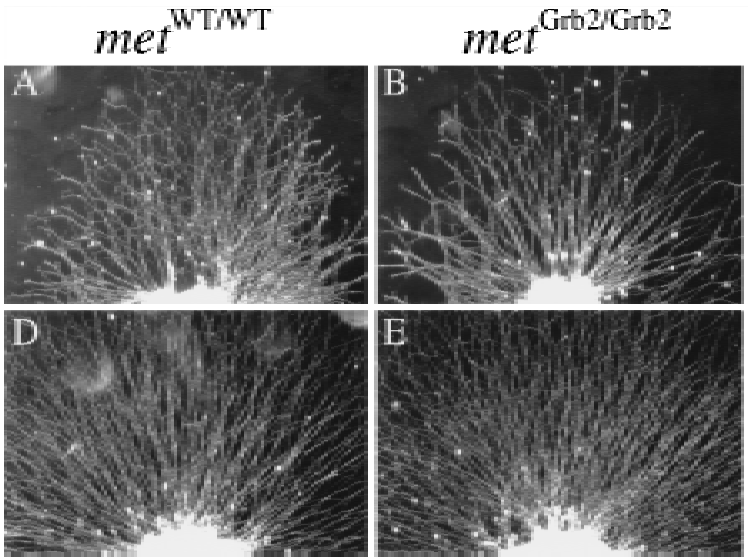

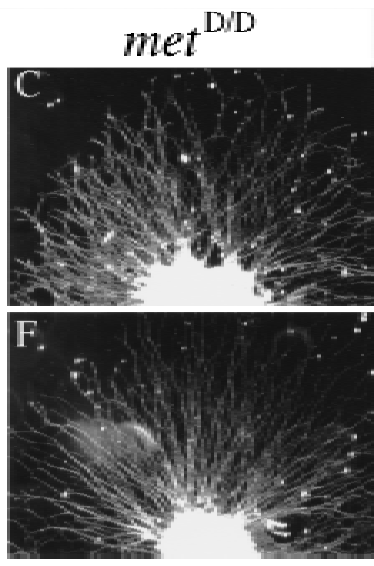

Figure 4. Neurite outgrowth of DRG explants from met mutant embryos. Photomicrographs of DRGs from E12.5 met $^{W T / W T}(A, D)$, met ${ }^{G r b 2 / G r b 2}(B, E)$, and met $^{\mathrm{D} / \mathrm{D}}(\mathrm{C}, \mathrm{F})$ mutant embryos, cultured for $20 \mathrm{hr}$ either in the presence of N GF only (5 $\mathrm{ng} / \mathrm{ml}$ ) (A-C) or with HGF (12ng/ml) (D-F). In three separate experiments, performed in quadruplicate, no significant HGF effect was observed in DRG explants derived from met ${ }^{\mathrm{D} / \mathrm{D}}$ mutants. 

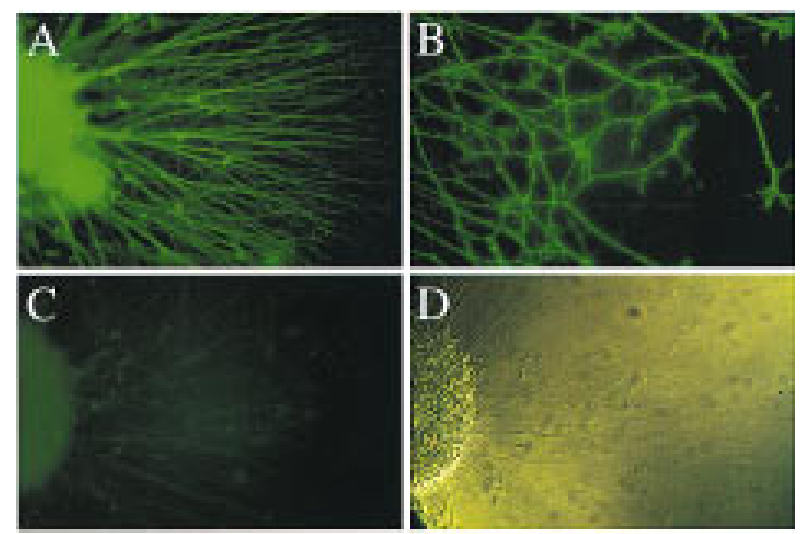

$\mathrm{E}$

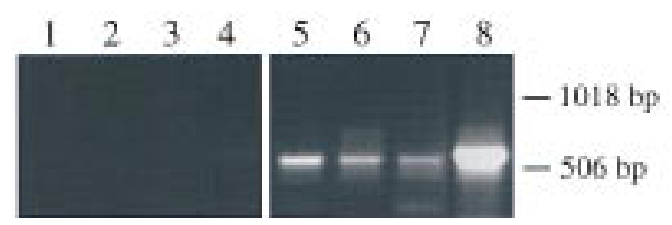

Figure 5. M et receptor expression in the axons of sensory neurons stimulated by N GF plus HGF in vitro. (A,B) Immunofluorescence of DRG explants from met ${ }^{\mathrm{Grb2} / \mathrm{Grb2}}$ mutant embryos, cultured in the presence of NGF plus HGF and stained with an affinity-purified polyclonal antibody against human $M$ et protein. Because these mice carry the human CDNA in the met locus, the chimeric $M$ et protein can be specifically recognized by the anti-human $M$ et antibodies against the unique carboxyterminal peptide. $\mathrm{N}$ ote the expression of $\mathrm{M}$ et receptors in the axons and growth cones of cultured DRG neurons. (C) The M et signal is completely blocked with the antigenic peptide. (D) Phase-contrast image of the DRG explant, shown in C, to visual ize the axons. M agnification: $20 \times(A, C, D) ; 40 \times(B)$. (E) RT-PCR analysis of $M$ et expression in dissociated DRG neuron cultures treated with NGF +HGF (lanes 1,5), NT3 +HGF (lanes 2,6) or BDNF + HGF (lanes 3,7) and in intact DRGs (lanes 4,8; shorter exposure of lane 8). Dissociated cultures were substantial ly pure with only $5 \%-10 \%$ non-neuronal cells, indicating M et expression in neurons. Lanes 5-8 show the expected met-specific 550bp DNA fragment in an ethidium bromide-stained agarose gel. These data were confirmed by Southern blot using an internal met-specific oligonucleotide probe (data not shown). In lanes 1-4 PCR analysis was performed without reverse transcription reaction.

outgrowth (E12.5) revealed an approximately twofold increase in the number of apoptotic ganglion cells in met $^{\mathrm{D} / \mathrm{D}}$, compared to age-matched met ${ }^{\mathrm{WT} / \mathrm{WT}}$ or heterozygous mutants (Fig. 8A,B). These results suggest that $M$ et receptor signaling is required for the survival of a subset of DRG neurons in vivo. As the same levels of increased cell death are observed over 2 consecutive days, one would expect the final numbers of DRG neurons to be si gnificantly reduced. Interestingly, the mi lder signaling mutant met ${ }^{\mathrm{Grb2} / \mathrm{Grb2}}$ did not show any increase in apoptotic DRG neurons, indicating that $M$ et signaling via Grb2 is not required for its neurotrophic activities.

\section{Discussion}

Our results show that $\mathrm{HGF} / \mathrm{M}$ et signaling enhances axonal growth and survival of peripheral sensory neurons both in vitro and in vivo. These effects are likely to be attributable to a direct action of HGF on sensory neurons for the following reasons: (1) M et is expressed by DRG neurons at the time met mutant mice develop deficits; (2) HGF is produced by mesenchymal cells at the right time of embryonic development (Sonnenberg et al. 1993; Thery et al. 1995) to act on DRG neurons; (3) the target of most sensory neurons, the skin, appears to develop normally in met mutant mice ( $F$. Maina and R. Klein, unpubl.), arguing against indirect effects caused by abnormal development of the target; (4) HGF enhances the growth of sensory axons in vitro; and (5) HGF increases the number of neurons that differentiate from progenitor cells and enhances the survival of these early neurons in the presence of NGF.

Recently, HGF has been shown to be a survival factor for cultured motoneurons (Ebens et al. 1996; Wong et al. 1997; Yamamoto et al. 1997). Although these findings suggest a physiological role of HGF/Met in the regulation of motoneuron survival, it remains to be demonstrated whether HGF, like many other motoneuron survival factors, is required for in vivo survival (Oppenheim 1996). The defects in hgf $-1-$ (Ebens et al. 1996) and met mutant mice (this study) do not indicate a direct role for HGF in regulating motoneuron numbers. The tight correlation between loss of muscle and defects in limb nerve branching in met ${ }^{\mathrm{Grb2} / \mathrm{Grb2}}$ mutants (Fig. 1) argues in favor of the idea that the motor nerve defects are secondary to loss of muscle target cells.

Using the met ${ }^{\mathrm{Grb2} / \mathrm{Grb2}}$ mutant mice, we have shown

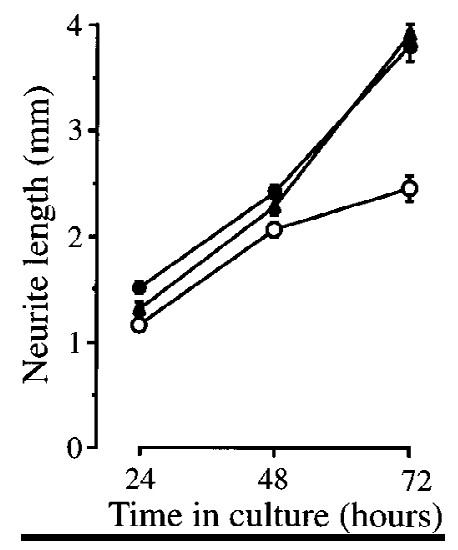

Figure 6. HGF cooperates with NGF to enhance axonal growth of dissociated sensory neurons. Graph of the axonal growth rates of E12 DRG neurons incubated with NGF alone $(O)$ or with NGF + HGF at $5 \mathrm{ng} / \mathrm{ml}(\bullet)$ and $25 \mathrm{ng} / \mathrm{ml}(\mathbf{\Lambda})$. The means and standard errors of serial measurements of between 79 and 89 neurons in each experimental group (compiled from three separate experiments) are shown. The neurites of neurons growing with N GF + HGF were significantly longer than those growing with N GF al one at all time points ( $P$ values ranging between 0.023 and $\varangle$ $\varangle 0001$; t-tests). 
A

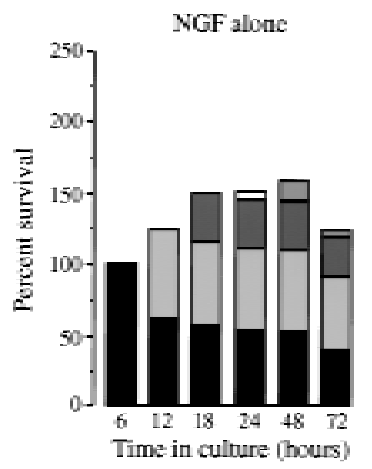

$\mathbb{B}$

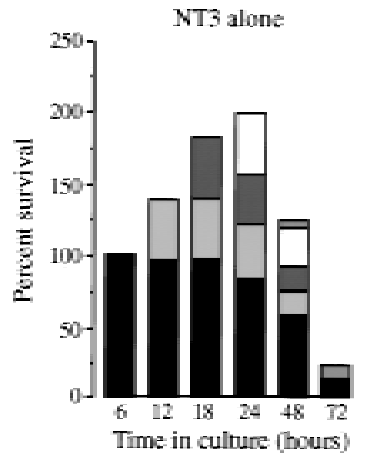

C

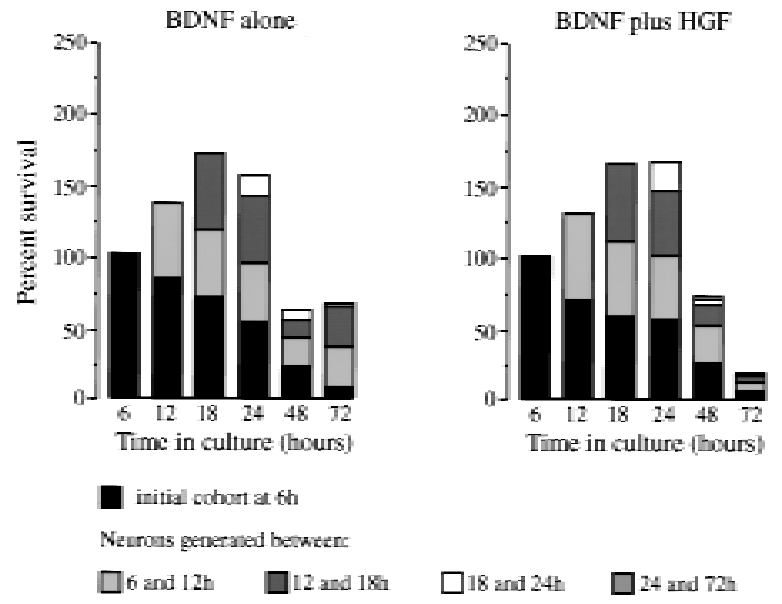

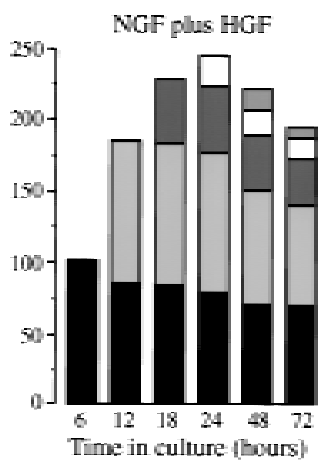

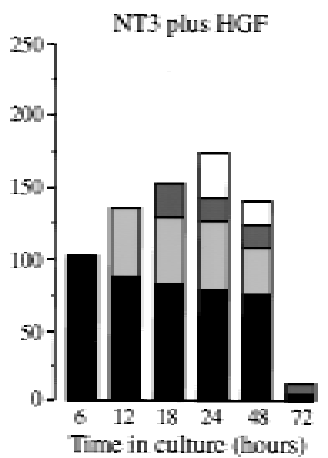

Figure 7. HGF cooperates with NGF, but not NT3 or BDNF, to enhance differentiation of progenitors and survival of dissociated DRG neurons. Bar charts of the survival of neurons that differentiate at intervals in cultures of E12 thoracic DRG neurons grown with $5 \mathrm{ng} / \mathrm{ml}$ of N GF al one or $5 \mathrm{ng} / \mathrm{ml}$ of N GF plus $5 \mathrm{ng} / \mathrm{ml} \mathrm{HGF}(\mathrm{A})$, with $5 \mathrm{ng} / \mathrm{ml}$ of NT3 al one or $5 \mathrm{ng} / \mathrm{ml}$ of NT3 plus $5 \mathrm{ng} / \mathrm{ml}$ of HGF (B), or with $5 \mathrm{ng} / \mathrm{ml}$ of BDNF alone or 5 $\mathrm{ng} / \mathrm{ml}$ BDNF plus $5 \mathrm{ng} / \mathrm{ml}$ of HGF (C). Similar results were obtained in three other experiments of each kind (data not shown).

recently that uncoupling of Grb2 from the Met receptor does not interfere with the devel opment of placenta and liver (M aina et al. 1996). In contrast, a direct link of M et with Grb2 is required for the development of muscles (Maina et al. 1996). This suggests that full activation of the Ras/M APK (mitogen activated protein kinase) path- way is required to promote proliferation of myoblasts. Here, we show that axonal branching and survival of sensory neurons are mediated by $M$ et effectors distinct from Grb2. Candidate effectors include the recently identified Met-binding protein Gab-1 (Weidner et al. 1996), whose interaction with the receptor should not be perturbed by this mutation. $\mathrm{N}$ ew signaling mutants of $M$ et are being generated to refine further the individual roles of Met-activated signaling pathways in vivo. Because $M$ et mediates different biological functions in DRGs, it will be very interesting to test which signal transduction pathways are required for each function in this system.

Our in vitro assays have shown that HGF al one is inactive and that it requires the presence of NGF for its axonal outgrowth and survival-promoting activities on DRG neurons, suggesting that in these cells, the downstream signaling pathways of $M$ et and the N GF receptor,
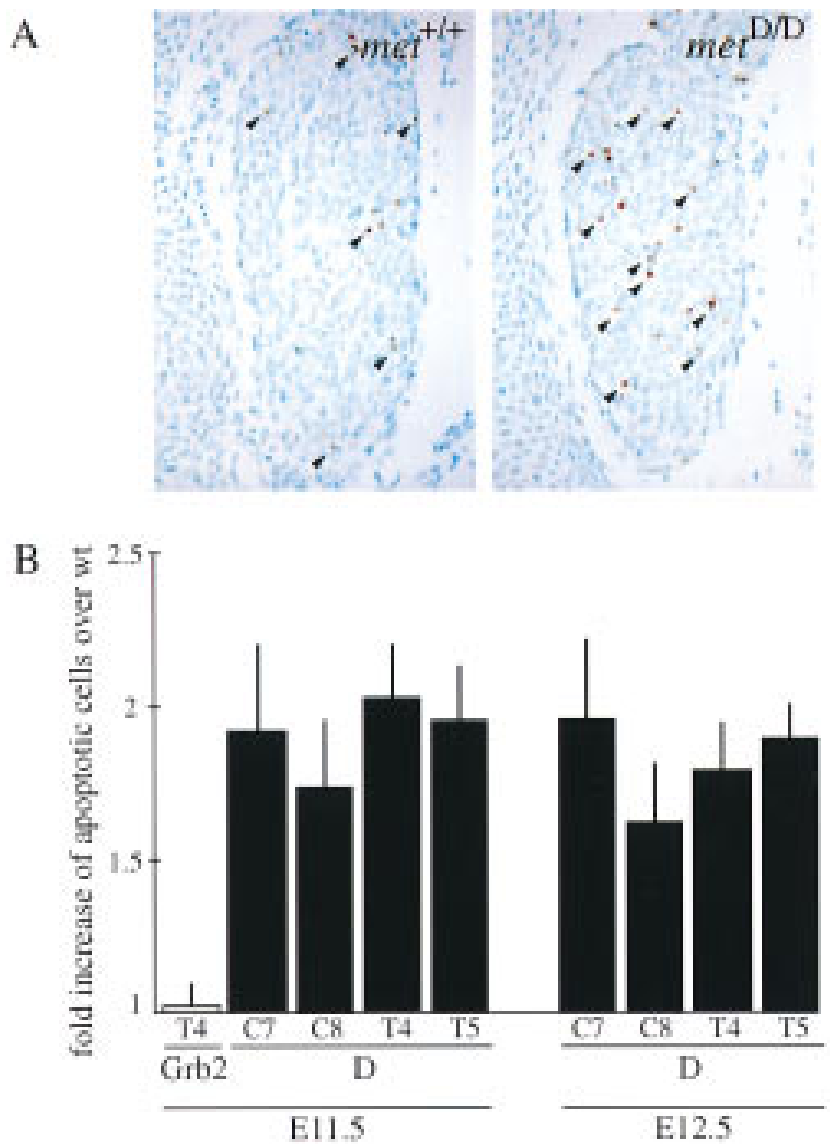

Figure 8. M et signaling is required for the survival of a subset of DRG neurons in vivo. (A) Photomicrographs of equivalent sections of E12.5 DRGs of wild-type (left) and met ${ }^{\mathrm{D} / \mathrm{D}}$ mutant mice (right) -- stained by the TUNEL technique (some apoptotic cells are indicated with arrowheads). (B) Quantitative analysis of the number of apoptotic (TUNEL-positive) cells in E11.5 and E12.5 cervical $(C 7, C 8)$ and thoracic $(T 4, T 5)$ DRGs of met $^{\mathrm{Grb} 2 / \mathrm{Grb} 2}$ (Grb2) and met ${ }^{\mathrm{D} / \mathrm{D}}$ (D) mutant mice (P values ranging between 0.04 and $\varangle$.001; t-tests). 
TrkA, converge. This is different from the situation in motoneurons, where HGF al one is effective in promoting the survival of motor neurons in culture (Ebens et al . 1996; Wong et al. 1997; Yamamoto et al. 1997). It remains to be determined whether or not HGF can act synergistically with neurotrophins in this system. Interestingly, HGF is unable to enhance the activities of N GF on another population of sensory neurons located in the trigeminal ganglion, indicating that effects of HGF are not attributable to generalized increased fitness of sensory neurons (A. Forgie and A.M. Davies, unpubl.). In support of this observation, we have been unable to find defects in outgrowth or branching of peripheral trigeminal nerves ( $F$. Maina and $R$. Klein, unpubl.). Our results indicate the presence of cell type-specific effector(s) of TrkA whose signaling is enhanced by activated Met receptors, either by stabilizing signaling activities or by bl ocking a specific inhibitor of the TrkA pathway. So far, we have no evidence for possible interactions between M et and TrkB or TrkC, the receptors for BDN F and NT3, respectively (Klein 1994; Barbacid 1995).

N GF and its receptor TrkA are important for the survival of pain and temperature-sensitive DRG neurons whose peripheral axons largely terminate in the skin (Crowley et al. 1994; Smeyne et al. 1994; Wall 1995; Indo et al. 1996). The dual requirement observed in vitro of HGF and NGF explains the lack of superficial nerve branches in the skin of met ${ }^{D / D}$ mutant embryos. NGF is currently being developed as a therapeutic drug for the treatment of peripheral sensory neuropathies, often observed in human patients suffering from diabetes or cancer therapy (Barinaga 1994). Considering the strong enhancement of NGF-induced sprouting by HGF, combinations of the two factors may prove to be even more effective ( $\mathrm{N}$ ishi 1994).

\section{Materials and methods}

\section{Whole-mount immunohistochemistry}

Generation and initial phenotypic analysis of met ${ }^{\mathrm{WT} / \mathrm{WT}}$, met $^{\mathrm{Grb2/G} \text { rb2} \text {, and met }}{ }^{\mathrm{D} / \mathrm{D}}$ knock-in mutant mice were previously described (Maina et al., 1996). E12.5 and E13.5 embryos were fixed overnight at $4^{\circ} \mathrm{C}$ in Dent's fixative (1:4, DMSO/ methanol), bleached in $\mathrm{H}_{2} \mathrm{O}_{2}\left(1: 2,30 \% \mathrm{H}_{2} \mathrm{O}_{2}\right.$ / Dent's fixative) at room temperature, and incubated overnight with anti-NF160 antibody (N-5264; Sigma) or anti- $\beta$-Tubulin Isotype III (T-8660; Sigma). After washing with TBS (10 mM Tris- $\mathrm{HCl}$ at $\mathrm{pH} 8.0,100$ $\mathrm{mm} \mathrm{NaCl}$ ), embryos were incubated overnight with secondary antibody (goat anti-mouse IgG-conjugated with horseradish peroxidase, Fab fragment, A-3682; Sigma). After several washes in TBS, embryos were stained with diaminobenzidine and $\mathrm{H}_{2} \mathrm{O}_{2}$. After staining, the embryos were cleared by dehydrating in methanol and incubated first in 50\% BABB (1:2, benzyl al cohol / benzyl benzoate) and finally in $100 \%$ BABB.

\section{In situ detection of apoptosis}

Paraffin-embedded embryo sections $(7 \mu \mathrm{m})$ were deparaffinized, incubated in $\mathrm{H}_{2} \mathrm{O}$ containing $0.3 \% \mathrm{H}_{2} \mathrm{O}_{2}$ for $30 \mathrm{~min}$, washed, and incubated with proteinase $\mathrm{K}(2 \mu \mathrm{g} / \mathrm{ml})$ in PBS for $8 \mathrm{~min}$ at room temperature. A poptotic cells were detected as described in the In Situ Cell Death Detection Kit, POD (Boehringer). Sections were counterstained with methyl green.

\section{RT-PCR and Southern blot}

RNA was extracted from E12.5 DRGs and primary neurons treated for $24 \mathrm{hr}$ with N GF plus HGF, NT3 plus HGF or BDN F plus HGF, using the acid phenol-chloroform method (Chomczynski and Sacchi 1987), and subjected to reverse transcription with oligo(dT) $)_{15}$ primers and PCR amplification. The met-specific primers were as follows: 5'-AGAGACCAGCAGCTTCAGTTACCG-3' (sense primer corresponding to nucleotides 21892213 of mouse c-met cDNA) and 5'-CCACTCTATATTTAGCTCGCTGTTCAG-3' (antisense primer corresponding to nucleotides 2704-2730). A met-specific oligonucleotide (5'-AGAGTGCCAGTGGAGACTCTCGCAGCTCTG-3'; antisense primer corresponding to nucleotides 2635-2684), internal to the PCR product, was labeled with $\left[\gamma^{-32}\right.$ ATP using the T4 polynucleotide kinase and used as probe for the Southern blot.

\section{Neurite outgrowth assays}

DRGs from E12.5 wild-type CD 1 or mutant $129 \times$ C57B1/ 6 embryos were dissected and cultured in tissue culture dishes coated with poly-L-ornithine and Iaminin in Dulbecco's modified Eagle medium/F12 (DMEM / F12) (Puschel et al. 1996), with the indicated growth factors. NGF and monoclonal anti-NGF antibodies were purchased from Boehringer Mannheim; BDNF and NT 3 were generously provided by Regeneron Pharmaceuticals. Polyclonal anti-HGF antibodies were purchased from $R \& D$ Systems.

\section{Quantification of outgrowth activity}

The density of neurite outgrowth was analyzed by measurement and comparison of digitalized micrographs (800-bpi resoIution) with the N IH-Image 1.6 program (devel oped at the U.S. $\mathrm{N}$ ational Institutes of Health and available on the Internet at http://rsb.info.nih.gov/nih-image/). Circular areas were selected in four different positions at two distances from the DRG (to obtain additional data on neurite length). The mean intensity was measured as the sum of intensities of all pixels in the area divided by the total number of pixels per area. In addition, for each image analyzed, the mean intensity of areas (2-4) containing no neurites was measured and subtracted as background.

\section{Immunofluorescence staining}

DRG explants were fixed in methanol, washed with PBS followed by PBS plus $0.3 \%$ Tween, before incubating with blocking solution for $30 \mathrm{~min}$ and with primary antibody for $1 \mathrm{hr}$. The antibodies used were anti-mouse-M et (polyclonal sc-162, Santa Cruz), anti-human-Met (affinity-purified polyclonal sc-161, Santa Cruz) and affinity-purified fluorescein (FITC)-conjugated goat anti-rabbit (Jackson Immunoresearch Laboratories). For neutralization, the antibodies against $M$ et were incubated for 2 $\mathrm{hr}$ at room temperature with a 10-fold excess of the corresponding peptide antigen.

\section{Neuronal cultures}

Thoracic DRG from E12 mouse embryos were trypsinized, dissociated, and plated at low density (500-2000 per dish) in serum- 
free medium in 60-mm petri dishes that had been coated with poly-L-ornithine and Iaminin (Paul and Davies 1995). To study the effects of neurotrophins and HGF on the differentiation and survival of neurons, the fate of individual cells was followed at intervals in these cultures (Paul and Davies 1995). The locations of all neurons within a 144- $\mathrm{mm}^{2}$ grid were recorded $6 \mathrm{hr}$ after plating as were the locations of all neurons that subsequently differentiated from progenitor cells at further time intervals in the same grid. The fates of all of the neurons in each of these cohorts (alive or dead) was followed at intervals up to $72 \mathrm{hr}$ in culture. The number of surviving neurons in each cohort is expressed as a percentage of the size of the initial cohort identified at $6 \mathrm{hr}$. N eurotrophins and HGF were added to the cultures with the identification of the initial cohort at $6 \mathrm{hr}$. To study the effect of NGF and HGF on axonal growth rate, accurate serial drawings of the same neurons were made with a drawing tube from which total neurite length was calculated as described previously (Davies 1989). The length measurements reported were not influenced by any differences in neuronal survival under the different experimental conditions used because only neurons that survived the entire culture period (up to $72 \mathrm{hr}$ ) were included in the analysis.

\section{Acknowledgments}

We thank R. A dams for help with DRG cultures, R. Saffrich for help with quantification of DRG neurite outgrowth, Genentech for providing recombinant HGF, and Regeneron Pharmaceuticals for recombinant BDNF and NT3. Part of this work was supported by a European Commission Biotechnology network grant (to R.K. and A.M.D.) and by Telethon-Italy (to C.P.).

The publication costs of this article were defrayed in part by payment of page charges. This article must therefore be hereby marked "advertisement" in accordance with 18 USC section 1734 solely to indicate this fact.

\section{References}

Andermarcher, E., M.A. Surani, and E. Gherardi. 1996. Co-expression of the HGF/SF and c-met genes during early mouse embryogenesis precedes reciprocal expression in adjacent tissues during organogenesis. Dev. Genetics 18: 254-266.

Barbacid, M. 1995. Neurotrophic factors and their receptors. Curr. Opin. Cell Biol. 7: 148-155.

Barinaga, M. 1994. Neurotrophic factors enter the clinic. Science 264: 772-774.

Bladt, F., D. Riethmacher, S. Isenmann, A. Aguzzi, and C. Birchmeier. 1995. Essential role for the c-met receptor in the migration of myogenic precursor cells into the limb bud. $\mathrm{Na}$ ture 376: 768-771.

Brinkmann, V., H. Foroutan, M. Sachs, K.M. Weidner, and W. Birchmeier. 1995. Hepatocyte growth factor/scatter factor induces a variety of tissue-specific morphogenic programs in epithelial cells. J. Cell Biol. 131: 1573-1586.

Chomczynski, P. and N. Sacchi. 1987. Single step method of RNA isolation by acid guanidinium thiocyanate-phenolchloroform extraction. A nal. Biochem. 162: 156-159.

Crowley, C., S.D. Spencer, M.C. N ishimura, K.S. Chen, S. PittsMeek, M.P. Armanini, L.H. Ling, S.B. McMahon, D.L. Shelton, A.D. Levinson, and H.S. Phillips. 1994. Mice lacking nerve growth factor display perinatal loss of sensory and sympathetic neurons yet devel op basal forebrain cholinergic neurons. Cell 76: 1001-1012.

Davies, A.M. 1989. Intrinsic differences in the growth rate of early nerve fibres related to target distance. Nature 337: 553555.
-——. 1994. Role of neurotrophins in the developing nervous system. J. Neurobiol. 25: 1334-1348.

Ebens, A., K. Brose, E.D. Leonardo, M.G. Hanson, F. Bladt, C. Birchmeier, B.A. Barres, and M. Tessier-Lavigne. 1996. Hepatocyte growth factor/Scatter factor is an axonal chemoattractant and a neurotrophic factor for spinal motor neurons. Neuron 17: 1157-1172.

Epstein, J.A., D.N . Shapi ro, J. Cheng, P.Y.P. Lam, and R.L. M aas. 1996. Pax3 modulates expression of the c-M et receptor during limb muscle development. Proc. Natl. Acad. Sci. 93: 4213-4218.

Farinas, I., C.K. Yoshida, C. Backus, and L.F. Reichardt. 1996. Lack of neurotrophin-3 results in death of spinal sensory neurons and premature differentiation of their precursors. Neuron 17: 1065-1078.

Franz, T., R. Kothary, M.A. Surani, Z. Halata, and M. Grim. 1993. The Splotch mutation interferes with muscle development in the limbs. Anat. Embryol. 187: 153-160.

Gherardi, E. and M. Stoker. 1991. Hepatocyte growth factorscatter factor: Mitogen, motogen, and met. Cancer Cells 3: 227-232.

Goodman, C.S. and C.J. Shatz. 1993. Developmental mechanisms that generate precise patterns of neuronal connectivity. Cell/ Neuron (Suppl.) 72/10: 77-98.

Henderson, C.E. 1996. Role of neurotrophic factors in neuronal development. Curr. O pin. Neurobiol. 6: 64-70.

Indo, Y., M. Tsuruta, Y. Hayashida, M.A. Karim, K. Ohta, T. Kawano, H. Mitsubuchi, H. Tonoki, Y. A waya, and I. Matsuda. 1996. Mutations in the TRKA/NGF receptor gene in patients with congenital insensitivity to pain with anhidrosis. Nature Genet. 13: 485-488.

Jung, W., E. Castren, M. Odenthal, G.F. Vande Woude, T. Ishii, H.-P. Dienes, D. Lindholm, and P. Schirmacher. 1994. Expression and functional interaction of hepatocyte growth factor-scatter factor and its receptor c-met in mammalian brain. J. Cell Biol. 126: 485-494.

Kennedy, T.E. and M. Tessier-Lavigne. 1995. Guidance and induction of branch formation in developing axons by targetderived diffusible factors. Curr. O pin. Neurobiol. 5: 83-90.

Klein, R. 1994. Role of neurotrophins in mouse neuronal development. FASEB J. 8: 738-744.

Lewin, G.R. and Y.-A. Barde. 1996. Physiology of the neurotrophins. Annu. Rev. Neurosci. 19: 289-317.

Lewis, J., A. Chevallier, M. Kieny, and L. Wol pert. 1981. M uscle nerve branches do not develop in chick wings devoid of muscle. J. Embryol. Exp. Morphol. 64: 211-232.

Maina, F., F. Casagranda, E. Audero, A. Simeone, P. Comoglio, R. Klein, and C. Ponzetto. 1996. Uncoupling of Grb2 from the $M$ et receptor in vivo reveals complex roles in muscle development. Cell 87: 531-542.

M CAllister, A.K., D.C. Lo, and L.C. Katz. 1995. Neurotrophins regulate dendritic growth in developing visual cortex. Neuron 15: 791-803.

N ishi, R. 1994. N eurotrophic factors: Two are better than one. Science 265: 1052-1053.

Oppenheim, R.W. 1996. Neurotrophic survival molecules for motoneurons: An embarrassment of riches. Neuron 17: 195197.

Paul, G. and A.M. Davies. 1995. Sensory neurons require extrinsic signals to switch neurotrophin dependence during the early stages of target field innervation. Dev. Biol. 171: 590605.

Ponzetto, C., A. Bardelli, Z. Zhen, F. Maina, P. dalla Zonca, S. Giordano, A. Graziani, G. Panayotou, and P. Comoglio. 1994. A multifunctional docking site mediates signaling and transformation by the hepatocyte growth factor/scatter fac- 
tor receptor family. Cell 77: 261-271.

Ponzetto, C., Z. Zhen, E. Audero, F. Maina, A. Bardelli, M.L. Basile, S. Giordano, R. Narsimhan, and P.M. Comoglio. 1996. Specific uncoupling of GRB2 from the M et receptor: Differential effect on transformation and motility. J. Biol. Chem. 271: 14119-14123.

Puschel, A.W., R.H. Adams, and H. Betz. 1996. The sensory innervation of the mouse spinal cord may be patterned by differential expression of and differential responsiveness to semaphorins. Mol. Cell. Neurosci. 7: 419-431.

Schmidt, C., F. Bladt, S. Goedecke, V. Brinkmann, W. Zschlesche, M. Sharpe, E. Gherardi, and C. Birchmeier. 1995. Scatter factor/hepatocyte growth factor is essential for liver development. Nature 373: 699-702.

Schnell, L., R. Schneider, R. Kolbeck, Y.A. Barde, and M.E. Schwab. 1994. N eurotrophin-3 enhances sprouting of corticospinal tract during devel opment and after adult spinal cord lesion. Nature 367: 170-173.

Smeyne, R.J., R. Klein, A. Schnapp, L.K. Long, S. Bryant, A. Lewin, S.A. Lira, and M. Barbacid. 1994. Severe sensory and sympathetic neuropathies in mice carrying a disrupted Trk/ N GF receptor gene. Nature 368: 246-249.

Sonnenberg, E., D. Meyer, K.M. Weidner, and C. Birchmeier. 1993. Scatter factor/hepatocyte growth factor and its receptor, the c-met tyrosine kinase, can mediate a signal exchange between mesenchyme and epithelia during mouse development. J. Cell Biol. 123: 223-235.

Thery, C., M.J. Sharpe, S.J. Batley, C.D. Stern, and E. Gherardi. 1995. Expression of HGF/SF, HGFI/MSP, and c-met suggests new functions during early chick development. Dev. Genet. 17: 90-101.

Uehara, Y., O. Minowa, C. Mori, K. Shiota, J. Kuno, T. N oda, and N. Kitamura. 1995. Placental defect and embryonic lethality in mice lacking hepatocyte growth factor/scatter factor. Nature 373: 702-705.

Wall, P.D. 1995. Independent mechanisms converge on pain. Nature Med. 1: 740-741.

Weidner, K.M., S. Di Cesare, M. Sachs, V. Brinkmann, J. Behrens, and W. Birchmeier. 1996. Interaction between Gab1 and the c-M et receptor tyrosine kinase is responsible for epithelial morphogenesis. Nature 384: 173-176.

White, F.A., I. Silos-Santiago, D.C. Molliver, M. Nishimura, H. Phillips, M. Barbacid, and W.D. Snider. 1996. Synchronous onset of NGF and TrkA survival dependence in developing dorsal root ganglia. J. Neurosci. 16: 4662-4672.

Wong, V., D.J. Glass, R. Arriaga, G.D. Yancopoulos, R.M. Lindsay, and G. Conn. 1997. Hepatocyte growth factor promotes motor neuron survival and synergizes with ciliary neurotrophic factor. J. Biol. Chem. 272: 5187-5191.

Yamamoto, Y., J. Livet, R. Vejsada, R.A. Pollock, V. Arce, O. deLapeyriere, A.C. Kato, and C.E. Henderson. 1997. Hepatocyte growth factor (HGF/SF) is a muscle-derived survival factor for a subpopulation of embryonic motoneurons. Development 124: 2903-2913. 


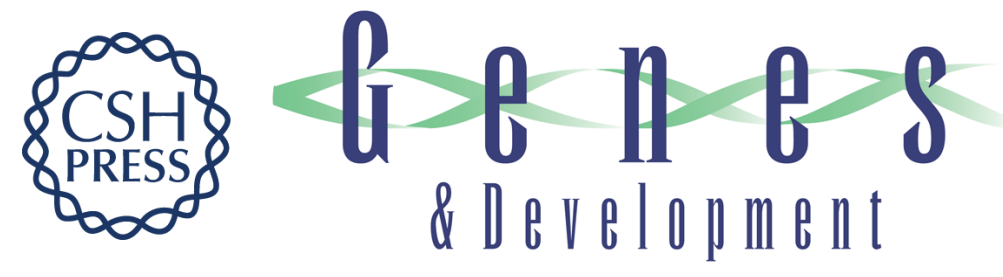

\section{Met receptor signaling is required for sensory nerve development and HGF promotes axonal growth and survival of sensory neurons}

Flavio Maina, Mark C. Hilton, Carola Ponzetto, et al.

Genes Dev. 1997, 11:

Access the most recent version at doi:10.1101/gad.11.24.3341

References

This article cites 40 articles, 10 of which can be accessed free at: http://genesdev.cshlp.org/content/11/24/3341.full.html\#ref-list-1

License

Email Alerting

Receive free email alerts when new articles cite this article - sign up in the box at the top Service right corner of the article or click here.

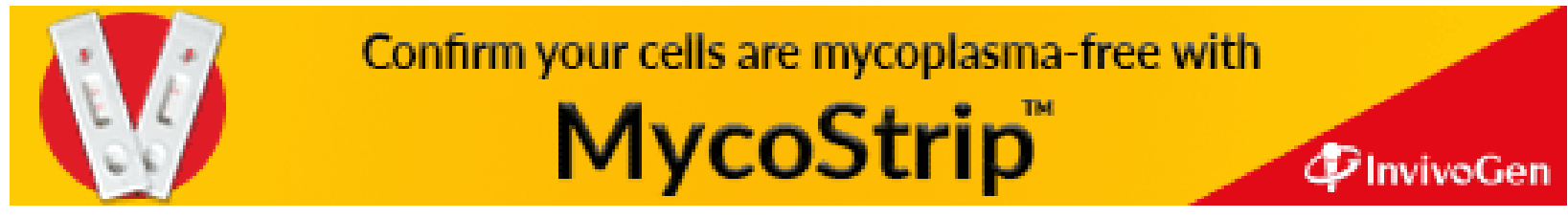

